\title{
The Changing Paradigms in Lifestyle Marketing - A Case Study Approach with Reference to Watch Industry
}

\author{
Priti K. Rao \\ Assistant Professor, Srinivas Institute of Management Studies, Pandeshwar, Mangalore - \\ 575001, INDIA. \\ E-mail: pritijeevan@gmail.com
}

Type of the Paper: Case Study Article.

Type of Review: Peer Reviewed.

Indexed In: OpenAIRE.

DOI: http://dx.doi.org/10.5281/zenodo.581161.

Google Scholar Citation: IJCSBE

\section{How to Cite this Paper:}

Priti K. Rao. (2017). The Changing Paradigms in Lifestyle Marketing - A Case Study Approach with Reference to Watch Industry. International Journal of Case Studies in Business, IT and Education (IJCSBE), 1(1), 27-34.

DOI: http://dx.doi.org/10.5281/zenodo.581161.

International Journal of Case Studies in Business, IT and Education (IJCSBE) A Refereed International Journal of Srinivas University, India.

(C) With Authors.

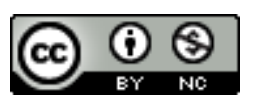

This work is licensed under a Creative Commons Attribution-Non Commercial 4.0 International License subject to proper citation to the publication source of the work.

Disclaimer: The scholarly papers as reviewed and published by the Srinivas Publications (S.P.), India are the views and opinions of their respective authors and are not the views or opinions of the S.P. The S.P. disclaims of any harm or loss caused due to the published content to any party. 


\title{
The Changing Paradigms in Lifestyle Marketing - A Case Study Approach with Reference to Watch Industry
}

\author{
Priti K. Rao \\ Assistant Professor, Srinivas Institute of Management Studies, Pandeshwar, Mangalore - \\ 575001, INDIA. \\ E-mail:pritijeevan@gmail.com
}

\begin{abstract}
Current business houses use the word "Lifestyle marketing" which is like a buzz word used in the selling and marketing in the present century. Lifestyle has a psychological determinant that influences buying behaviour- reflecting an individual's choice of how to spend money and time and the attitudes and values connected with these behavioural patterns. The success of an organization is directly linked to the level to which the company's products and marketing strategies, dominantly communication, which reflects the lifestyle of the targeted market. This aids in giving a competitive edge over the other business houses. This in turn generates revenue. The companies are forced to dedicate their marketing strategies towards life style marketing. This paper discusses the role of lifestyle marketing in the current business scenario and the strategies to be adopted by the watch industry to suit each target market and the branding and promotional techniques that influence the branding of various market segments. This will provide insights which are valuable for companies marketing and advertising strategies. As people's attitudes, interests and opinions regarding products and services change, it is vital for the marketers to continually monitor the changes. The basic objective of this paper "The changing paradigms in lifestyle marketing - A case study approach with reference to watch industry" aims at understanding the concept of lifestyle marketing and by utilizing this how the brand value can be made more effective be made. A case study approach using a watch sector as an example will be adopted to study this concept for better understanding and implications. The research uses secondary data for the collection of data. Conclusions, based on the outcome, hereby obtained were drawn and decisions were taken about the said objectives. The primary purpose of this paper is to stimulate further discussion amongst marketers and to be used in dialogue with stakeholders.
\end{abstract}

Keywords: Life Style Marketing, Branding, Consumer Behaviour, Watch Industry.

\section{INTRODUCTION :}

A lifestyle brand is an ideology created by a particular organisation's brand. It pursues to embody the identities, interests, lifestyles, attitudes and opinions of an individual, group or culture. An organisation achieves a lifestyle brand by focusing on evoking an emotional connection with its consumers. Therefore, organisation can create a desire for a consumer to be affiliated with a particular group or brand. Furthermore, the consumer will believe that their identity will be reinforced if they publicly associate themselves with a particular lifestyle brand. As individuals have different identities based on their personal experiences, choices or background (including social class, ethnicity or culture), an organisation must understand to whom it directs its brand. By operating off a lifestyle brand ideology, an organisation's ultimate goal is to become a recognised social phenomenon.

A lifestyle brand is a company that markets its products or services to embody the interests, attitudes, and opinions of a group or a culture. Lifestyle brands seek to inspire, guide, and motivate people, with the goal of their products contributing to the definition of the consumer's way of life. They often operate off an ideology, hoping to attract a relatively high number of people and ultimately becoming a recognised social phenomenon. 


\section{CONCEPTUAL FRAMEWORK :}

The definition of the term "lifestyle" itself is almost a tautology with many sources generally indicating that "lifestyle is the style in which a particular person lives." But that is in a very simple and colloquial sense. Lifestyle as a term originated in the context of the study of sociology in the 19th century, but later, in the mid 20th century, it became much more associated with media and marketing. It became tied to the "culture industry," where media sought to not only create culture, but also to package it.

In mid-19th century Japan, during the Meiji period, the country experienced a huge cultural shift. Japan was finally ending its feudal era system and was interested in enjoying much of the economic prosperity it observed from the West in Europe. A lot of interesting things happened during this period, but one notable example related to this discussion sticks out. Many influential Japanese politicians, thinkers, and even the emperor suggested that a very important way to enjoy the economics of the West was to simply dress and live like them. This was an early version of lifestyle marketing. Many Japanese people were encouraged to dress like Europeans so that Japan would be more like Europe [1]. For this reason, so many elements of Western culture to this day are an integral part of Japanese culture.

Lifestyle brands operate off the idea that each individual has an identity based on their choices, experiences, and background (e.g. ethnicity, social class, subculture, nationality, etc.). Lifestyle brands focus on evoking emotional connections between a consumer and that consumer's desire to affiliate him or herself with a group. Some recent contributions have defined lifestyle brands as one of the possible ways of consumer self-expression: customers believe that their identity will be reinforced or supplemented if they publicly associate themselves with a lifestyle brand or other symbolic-intensive brands [2].

\section{FACTORS THAT INFLUENCE CONSUMER DECISION PROCESS :}

It is evident that consumers in our modern world continually face multiple decisions with regard to product choice due to many competing products, such aspects as a product attributes have been shown to be involved in the consumer decision process. A number of factors can be identified that affect a consumer's choice of product brand which influences their lifestyle. Consumers are known to choose a brand that is acceptable to their self-image that they are trying to portray. This has left companies having to re-establish and position their products to ensure they meet the lifestyle a consumer is trying to obtain. They have an opportunity to refine their target market which would limit competition due to a reduced number in consumers who would be attracted to their specific brand because of the way they might perceive their lifestyle [3].

Consumers have a tendency to evaluate product attributes as opposed to a case by case assessment. There is the need for brands to be understood and how they can be influential with regard to consumer's decision making considerations. Three processes are identified as being intertwined in choice behaviour. These are psychological, sociological and economic processes. Within these three processes lifestyle of the consumer also becomes intertwined with consumers tending to choose a brand they feel is congruent with their self- image, their identity - who they feel they are and what they connect with the most. A consumer's value's, goals and vision for their life along with aesthetic style are all reflective of individual lifestyle [4].

\section{CONSUMER SELF-EXPRESSION :}

Consumers use brands to express their identity. The need for self-expression can be related to the need for acceptance within society and the societal view on brands and how different brands portray income or wealth. An advantage to lifestyle brands is that consumers can express their identity in a number of ways. This is a dominating factor that would lead on to the consumer adopting a certain lifestyle. Brands allow for customers to express themselves and portray their identity and lifestyle. Lifestyle brands in particular, portray a type of meaning that allows a particular reference group to attach themselves based on their lifestyle, values or beliefs [5].

\section{PERCEIVED BRAND VALUE :}

If a consumer loves fashion this will have a positive effect on his/her willingness to pay for a luxury, 
top end brand. In order for a lifestyle brand to be successful and dominate market share it needs to enhance customer's experiences and provide more than just a product. Consumers are more willing and likely to purchase a brand that establishes itself as to value and satisfaction. Brand value is defined as comparing focal brands with unbranded products that have had the same level/ same ways of marketing to consumers as well as adopting the same product attributes.

Luxurious brands target those that have an extreme lifestyle. Price is never a factor. Three categories are identified as measuring brand value: brand loyalty, perceived value and brand awareness/ association. Consumers associate themselves with luxury fashion brands to portray their certain lifestyle and separate them from the rest. Social value is an aspect that relates to consumers desire to obtain luxury brands that they hope will offer them a symbolic part of a group or culture. There are emotional factors that are connected to the consumption of a luxury brand, for example those that bring pleasure or excitement [6]. Consumers who purchase luxury brands tend to have a strong social function within their social class.

While "lifestyle" is not generally considered a negative term, calling someone a "poser" is. Posers act like people they aren't in order to relate to a group of people they don't actually belong in. Posers are people who are unsuccessful at adopting a lifestyle that is not what they feel comfortable with. Posers are what people want to avoid being, but the reality is that most lifestyle marketing is very much encouraging people to become posers.

\section{THE PRACTICE OF LIFE STYLE MARKETING :}

Lifestyle became the practice of identifying a particular class of people who had something enviable about them - and breaking down their interests, opinions, and way of life, fashion, and attitudes into various components. Breaking down these elements gave consumers a way to "enter" that lifestyle they found appealing by being able to mimic the choices of others who already have that lifestyle. Of course, if this sounds highly artificial, it is. The packaging of lifestyle isn't usually about helping people find new things to be interested in, but it is often packaged as a means of helping people to seek an ultimate goal - which is often about appearing more active, healthy, successful, or attractive, than one "normally" is.

A modern example of lifestyle marketing is the "active lifestyle." The most common manifestation of this is where individuals seek to benefit from the lifestyle of being active by dressing in clothes designed for exercise and often not actually exercising. Active lifestyle marketers promote a range of services and products to help make you feel as though you have an active lifestyle without necessarily actually having one. It's advisable not to waste the time trying to convince people to buy a product on its merits. It might not even be the best one around. Rather, focus on the illusion of how people are going to feel, look, and be perceived if they purchase a particular service or product.

Luxury prices are also associated with lifestyle marketing. "Only people in a particular class are even able to afford this product." Such messaging through pricing is another way of adding lifestyle marketing to the high-end watch industry. What happens is that rather than a brand pricing a timepiece as a function of its overall production cost, quality, and competitive value, the pricing reflects who a brand "hopes" should be wearing their products. Here, there is a firm disconnect between the qualitative nature of pricing, and the lifestyle-creating aspect of pricing.

Lifestyle marketing is about creating an idealized image and then offering people a way of "becoming more like that image" by purchasing a particular product or service. The emphasis is on how much the consumer wants to enjoy something that idealized image has, and in order to capture that, they are instructed to simply copy it. Thus, lifestyle marketing is about the perception that we gain attributes through mimicry - which is often not at all true, and to truly become an "authentic" member of a particular lifestyle, a lot more work or steps need to be taken [7].

\section{LIFESTYLE MARKETING CASE STUDY WITH REFERENCE TO WATCH SEGMENT :}

Watches are too often marketed with a focus on "who wears the brand," and "what types of things do owners of the watches do with them on their wrist." For this purpose, marketers have pictures of stylish people in formal attire or even celebrities wearing luxury watches. The idea is, "want to be more like them? Wear this product."Of course, the truth is that even if perception is $50 \%$ of reality, wearing most watches will not fundamentally change who you are - and savvy consumers know this. 
The bulk of watch advertising around the world focuses on the very simple formula of, "want to be like X, wear Y." This is totally apart from any actual message on why a particular product is interesting, useful, or noteworthy.

It's seen that people who spend a lot of time and money feeding their interest in watches do so for very technical reasons related to a timepiece's history, design, functionality, or inherent quality and artistry. Watch lovers are hungry for information about watches that will help them make personal decisions about what watch to buy. They make these decisions as a function of their own lifestyle and interests versus the lifestyle and interests of others. This helps explain why many watch lovers are seriously disinterested or even annoyed with things like celebrity ambassadors, and when a watch brand promotes their involvement with something related to fashion.

There's a general dissatisfaction among many consumers of watches when it comes to mass marketing and advertising for the watch brands. There has always seemed to be a major disconnect between the mentality of those people buying luxury watches and those people responsible for marketing said watches. This does not happen all the time, but as a general rule, luxury watch brand advertising does not seem to really attract the most serious enthusiasts who do things like regularly read about new watch releases and take the time to converse and meet with like-minded individuals. It begins with a term called "lifestyle." This term is used probably far too often in the world of marketing today, and when people say it, they refer to a marketing philosophy that emphasizes what people who use products might ideally be like, versus marketing the particular benefits or qualities of a product [8].

\section{MARKETING STRATEGIES FOR LIFESTYLE BRANDS :}

Marketing to watch lovers is so fruitful exactly because they are hungry for information, but the messages need to be appropriate. The company should explain the virtues of a watch and why it is so appealing; as opposed to creating a romantic scene that the brand would ideally like to see their watch existing within. That's lifestyle marketing, and it simply doesn't reach the needs of serious watch buyers.

Marketing is an invitation for a consumer to learn more. In this day and age, almost no major purchases are made without a consumer consulting a friend, expert, or review online. That also includes discussions of collectors and enthusiasts online via forums and possibly social media. That means individuals who are new to timepieces and are enticed by marketing material will often consult with exactly those people who are the most knowledgeable consumers. The point is that regardless of the sophistication level of a consumer who is viewing an advertisement, if they are interested enough in getting a luxury product; they will more likely than not read the opinions of people who have more expertise than themselves. Consumers around the world are increasingly educated and demanding. They hunger for information, transparency, and above all authenticity [9].

That should all be a clear message to watch marketers that creating lifestyle campaigns exclusively will cause them to miss out on many consumers or become susceptible to alienation from dedicated enthusiasts who might otherwise like their brand. Again, lifestyle marketing is designed to convey a message about what ideas and personality's consumers should associate with a brand.

Further, lifestyle marketing is more than just mass-market print, banner, and video campaigns. It also extends to social media campaigns such as those on places like Facebook and, notably, Instagram. Marketers should be careful not to dilute a brand's image or the perception of its products with too much falsity or promises of better lifestyles. Even when there is a focus on lifestyle campaigns, there should be equally heavy focus on "product merit campaigns."

Sales figures in most places around the world show direct correlations between marketing spending and sales success. Rolex sells an awful lot of watches in America, and also happens to be the top spender of marketing dollars. There is a huge association between a wide and regular proliferation of marketing messaging and buying habits. With that said, it should be the right marketing for the right consumer, and not marketing which alienates those people who are the most focused on a product such as watch enthusiasts [10].

When people buy a luxury Swiss watch, they are first buying a name and second buying a product. People are more interested in being part of a brand that they have been marketed to, versus acquiring the utility or craftsmanship of a particular item they will appreciate. Of course, there are occasionally 
buyers who are more immune to marketing, and who tend to focus on particular elements of a brand that they subjectively appreciate. With that said, while they may not be buying into a brand's particular flavour of product marketing, there is often "quiet marketing" in the form of storytelling that they are attracted to within that brand such as how they make products or the materials they use. In most instances, people aren't buying luxury products for utility any longer - and that is something which is difficult to deny. It is also something the traditional watch industry knows very well.

\section{PROBLEMS INVOLVED IN LIFE STYLE WATCH INDUSTRY :}

Lifestyle marketing comes at a time when the high-end watch industry is doing very poorly. It's not simply because of competition from smart watches - but the advent of emerging technology certainly doesn't help them. The luxury watch industry (mostly Swiss brands) is hurting due to stubborn reliance on archaic business practices in the form of sorely outdated distribution and pricing models. On top of that, the industry massively overproduces inventory - and the volume of unsold watches both in the market and being hoarded by brands is appallingly high. Some analysts contend that actually up to $50 \%$ of some watch brands' claimed value is in the form of unsold inventory assets. The luxury watch industry is where it is today because of marketing, and that is coming from someone who has traditionally been rather hard on marketing because Luxury watch marketing is actually quite weak. For an industry that sells much of its goods to men, they have taken a few too many lessons from women's fashion marketing. In fact, the only upside of how luxury watch brands market is in that they know consumers like to buy from "famous brands." The most success luxury watch makers have with marketing is name awareness. Rolex does happen to make a truly outstanding timepiece, but that isn't why they are so successful these days. Rolex is successful because of wide awareness of the brand name. Rolex is smart about the fact that their consumers want other people to notice the name on the watch on their wrist, and because of this the brand continues to enjoy wide demand. Having a well-made product without wide awareness will only make you a cult hit at best. Luxury brands like Rolex who spend money on both marketing and product have it figured out.

Unfortunately, many other luxury watch brands don't. When times are tough, most companies inevitably cut back on marketing and advertising spending. This might seem like a wise short-term solution, and it can be if the brand is going through some type of temporary change or reorganization and sales aren't a priority. When sales are a priority and the strengths of a brand must be asserted in order to assist in sales success that is when smart marketers must be put to work.

In addition to having deep-rooted systemic problems, the luxury watch industry also has an innovation problem. Marketing success during the 1990s and 2000s helped many brands earn a lot of money by placing status symbols on people's wrists, and making products for rich adults. Watch design and internal component has been for the most part stale. Innovation has been in the form of some new materials, and a small amount of new technology, mainly at the most high-end side of the industry. For the most part, consumers were being asked to buy new products that did not fundamentally offer anything different from previous generation products. Brands relied on collectors and value speculators in enthusiast communities to help them sell product. The problem was that these same collectors and communities are quickly becoming disillusioned with high prices, poor marketing, and a culture of discounting which has led to boredom at best, and distrust at worst when concerning many of the brands that formerly relied on their spirited enthusiasm. Thus, adding insult to injury, the luxury watch industry not only has to deal with the fact that they need to make some very painful changes to how they price, distribute, and sell their watches, but they also have a serious image problem when it comes to many of their core clientele. Nowadays when consumers are increasingly being offering alternatives to traditional mechanical watches and when luxury watch marketing is mostly of a poor quality, the Swiss watch industry needs to focus on making marketing a priority once again.

One of the fastest growing areas in the watch industry is small boutique brands with production coming out of China. Many of these brands use suppliers who produce parts for the big luxury brands. While the larger brands typically have a more polished product, these newer brands come to market with prices so much lower it begs the question to many consumers why there are so many brands charging so much more money. The watch industry desperately needs to realign their pricing models with consumer expectations, but they need to be more aware of the competitive market. In fact, many 
of these brands have decent reasons as to why their products cost a lot, but they don't explain that very well in their marketing materials. The luxury watch industry has pulled away so much marketing budget that the entire media industry dedicated to discussing it with consumers is dying out. The luxury watch industry currently still doesn't seem to fully understand that a strong luxury watch media is good for business. In a vividly self-effacing move, the watch industry has allowed the slow painful death of many business entities whose sole mission was to get people excited about purchasing a luxury watch.

Social media marketing will have some success, but it certainly isn't cheap. Moreover, brands need to invest in quality creative's and advertising campaigns so that they do not continue to make the mistakes of the past. For example, if you are going to market to men, then it is a good idea to produce marketing that is meant to be appeal to men. Further, the luxury watch industry has long been a fan of "exclusive" experiences, products, and availability. At some point, the watch industry will appreciate that a strong market for smart watches will be a strong market for luxury watches because in any situation where you have a large population of people using a particular type of product, there is by default interest in a high-end segment for well-to-do people to show off their status. Thus, if more people wear watches, the higher degree of attention on that product will lead people to luxury watches who can afford them.

\section{CONCLUSION :}

The appeal of luxury watches hasn't been about strict utility for a long time. Luxury watches are items of artistic craftsmanship often with appealing historic connections. The stories inherent to their heritage and construction are what get people excited about them. Luxury watch brand marketers need only to connect with many consumers on the right level to trigger their interest in the products. The watch industry needs to do is refocus its marketing creation efforts on high-quality messages that reach the right people. They also need to dedicate resources to market to those people. The fastest way for the luxury watch industry to increase its pain is to further stop marketing. Again, the luxury watch industry is a marketing-driven industry. So they better put some more effort into it. A company's status as a lifestyle brand isn't achieved by providing a wide range of products but by the benefit and symbolic value that the customer associates with the brand.

\section{REFERENCES :}

[1] Al, R., \& Jack, T. (1981). Positioning: The battle for your mind. New York: McGrawHill.

[2] Soderquist, D. (2005). The Wal-Mart way: the inside story of the success of the world's largest company. Thomas Nelson Inc.

[3] Moorthi, Y. L. (2000). Brand Management: The Indian Context. Vikas Publishing House.

[4] Clow, K. E. (2007). Integrated Advertising, Promotion and Marketing Communications, 4/e. Pearson Education India.

[5] Moriarty, S., Mitchell, N. D., Wells, W. D., Crawford, R., Brennan, L., \& Spence-Stone, R. (2014). Advertising: Principles and practice. Pearson Australia.

[6] Baran, R. J., Galka, R. J., \& Strunk, D. P. (2008). Principles of customer relationship management. Cengage Learning.

[7] Das, S. (2007). customer relationship management. Excel books.

[8] Dave, D. D., \& Dave, R. (2014). A study on Service quality and customer satisfaction of selected Private. Pacific Business Review International, 7-12.

[9] Kotler, P., \& Cox, K. K. (1980). Marketing management and strategy. Prentice Hall.

[10] Mukerjee, K. (2007). Customer Relationship Management: A Strategic Approach to Marketing. PHI Learning Pvt. Ltd.. 